\title{
Rapid resolution of toxoplasma chorioretinitis treatment using quadruple therapy
}

This article was published in the following Dove Press journal:

Clinical Ophthalmology

\author{
Arief Kartasasmita \\ Wendy P Muntur \\ Sutarya Enus \\ Erwin Iskandar
}

Faculty of Medicine, Universitas Padjadjaran, Cicendo National Eye Hospital, Bandung, Indonesia
Correspondence: Arief Kartasasmita Department of Ophthalmology, Universitas Padjadjaran, Jl. Cicendo

No 4, Bandung, 40I4I, Indonesia

Tel +62 224231280

Email a.kartasasmita@unpad.ac.id

Purpose: To compare the effectiveness of quadruple-drug therapy consisting of cotrimoxazole (trimethopin and sulfamethoxazole), clindamycin antibiotics, and oral corticosteroid versus triple therapy consisting of pyrimetamine, sulphadiazine, and oral corticosteroid in the resolution of toxoplasmic chorioretinitis.

Methods: This was a double-blind randomized controlled trial with repeated measures using parallel design to compare the effectiveness of quadruple-drug therapy and triple-drug therapy in patients with toxoplasmic chorioretinitis. The measurement of lesion was done using automated computer software, calculating the average of lesion size from three fundus photographs taken from the baseline and at each follow-up visit. The analytical statistics were obtained using Mann-Whitney test, comparing percentage of lesion remission test in each examination.

Results: The percentage of lesion remission in quadruple-drug therapy was higher than in triple-drug therapy from the first visit until the first follow-up visit, with a $p$-value of 0.001 . In addition, the mean percentage of lesion remission from first visit to last visit was $57.5 \%$ and the median was $70.9 \%$ in the quadruple therapy group, while in the triple-drug therapy group the mean was $52.5 \%$ and the median was $54.0 \%(p=0.720)$.

Conclusion: We conclude that the quadruple-drug therapy has a more rapid resolution effect on chorioretinitis lesion compared to triple therapy.

Keywords: toxoplasma chorioretinitis, quadruple-drug therapy, triple-drug therapy

\section{Introduction}

Ocular toxoplasmosis is a form of chorioretinitis caused by Toxoplasma gondii that is a potential cause of posterior uveitis that could lead to blindness. It is a progressive, recurring, and necrotizing condition, is associated with inflammation of the vascular structures of the retina and vitreous, and has a predilection to occur in the posterior pole in more than $50 \%$ of cases. ${ }^{1}$

Symptoms of ocular toxoplasmosis usually include a unilateral decrease in vision with floaters, accompanied by signs of anterior uveitis, and around $20 \%$ of patients have increased intraocular pressure. In the posterior segment, the condition classically appears as focal, grayish-white retinitis with overlying moderate vitreous inflammation, often adjacent to a pigmented chorioretinal scar. Although in most instances the diagnosis of toxoplasma chorioretinitis is predominantly clinical, the presence of anti-T. gondii IgG antibodies supports the diagnosis to a certain extent, whereas a negative antibody titer essentially rules out the diagnosis.

Visual loss caused by ocular toxoplasmosis arises from complications due to structural changes per se and the effects of associated intraocular inflammation. ${ }^{2}$ As the focal lesion of necrosis of the retina and choroid heals, a permanent punched-out retinochoroidal scar will develop; due to the high prevalence of the lesion occurring at the posterior pole, sight 
can be threatened. The inflammation process itself may create inadvertent complications that can lead to permanent conditions if left unattended in a timely manner. ${ }^{3}$ Therefore, faster therapy becomes effective, and the sooner it commences, the less the severity of damage, and hence visual impairment.

In immunocompetent patients, ocular toxoplasmosis has a self-limiting course of 6-8 weeks without treatment, but the disease course is more severe and progressive in immunocompromised cases. Currently, antibiotics combined with oral corticosteroid is the mainstay of chorioretinitis toxoplasma treatment. ${ }^{4,5}$ This current treatment does not effect a cure nor does it prevent recurrence; thus, there is no consensus regarding the most efficacious regimen. However, their role in therapy lies in minimizing the damaging effects of inflammation and limiting lesion size, particularly when sight is threatened.

The triple-drug therapy consisting two antibiotics (pyrimethamine and sulphadiazine) and one oral corticosteroid is standard treatment of toxoplasma chorioretinitis. However, taking into consideration the need for increasing efficacy in a more immediate manner to shorten parasitic replication, create rapid cicatrizing of the lesion, and limiting chorioretinal scars and progression, a quadruple-drug therapy has been considered that combines an additional antibiotic to the older regimen. ${ }^{6}$ Moreover, apart from the side effects of oral corticosteroids, the duration of treatment also become a consideration. ${ }^{7}$ Thus, the quadruple-drug therapy is also envisaged to minimize the corticosteroid side effects. ${ }^{8}$

Studies showed that there are no differences between the treatment outcome between the triple- and the quadruple-drug therapy. ${ }^{9}$ However, to our knowledge, there is no study that assessed the difference in efficacy of the quadruple therapy in shortening the duration of treatment compared with tripledrug therapy, in achieving the same treatment result to give rapid recovery and thus minimize the side effects.

To resolve this issue, we compared the efficacy and the treatment duration of triple-drug therapy and quadruple-drug therapy on chorioretinitis toxoplasma.

\section{Method}

This study was a randomized, single-blinded controlled trial study of patients with toxoplasma chorioretinitis who came to the Cicendo Eye Hospital, Bandung, Indonesia. The inclusion criteria are as follows: patients with a new case of chorioretinitis or those with recurrent disease with new lesions in a new location. The exclusion criteria were as follows: presence of vitreous opacities that interfere with the examination of retinal lesions, undergoing treatment or receiving antitoxoplasma therapy, and a history of allergy to the antibiotics used. The diagnosis of chorioretinitis was made by assessing the morphology of the retinal lesions by a vitreoretinal specialist supported by positive IgG toxoplasma titer data.

The ethical approval was obtained from Medical Research Ethics Commission of the Faculty of Medicine, Universitas Padjadjaran. After obtaining written informed consent, the samples were selected consecutively and divided into two groups, quadruple-drug therapy (Group I) and triple-drug therapy (Group II), using random block permutation methods.

Group I received a combination of two tablets of cotrimoxazole $480 \mathrm{mg}$ twice a day and oral clindamycin $300 \mathrm{mg}$ four times daily for 3 weeks. Group II received a combination of pyrimethamine tablet $25 \mathrm{mg}$, sulfadiazine tablet $1,000 \mathrm{mg}$, and oral methylprednisolone $1 \mathrm{mg} / \mathrm{kg} / \mathrm{d}$. Pyrimethamine is given three times daily at the start of therapy, and then tapered to once daily. Sulfadiazine is administered twice daily at the beginning, and then once daily, while corticosteroids are given $1 \mathrm{mg} / \mathrm{kg} / \mathrm{d}$ and tapered off each week. The combination of drugs is given for 3 weeks, with an addition of oral folic acid $5 \mathrm{mg}$ that is given three times per week interval alternate days. ${ }^{6}$

The result was obtained by comparing the reduction in the retinal lesion size between pretreatment and the third week of treatment. This assessment result was made by calculating the retinal lesion using AutoCAD 2012, version 18.2 (Autodesk Inc., San Rafael, CA, USA) computer software by a blinded trained technician. The data were then analyzed using the Mann-Whitney test. The result was considered significant with $p<0.05$.

The sample size was calculated using formula as described elsewhere: ${ }^{10} \mathrm{~N}=2 \sigma^{2}(\mathrm{Z} \alpha+Z \beta)^{2} / \mathrm{D}^{2}$ with significant level of $90 \%$, power test $80 \%$. In the formula, $\mathrm{N}=$ sample size; $\sigma=$ standard deviation; $Z \alpha=1.28$ (standard for $90 \%$ significancy); $Z \beta=0.84$ (standard for $80 \%$ power); $D=$ mean difference. From Soheilian et $\mathrm{al}^{11}$ the values we got were $\sigma=30$ and $\mathrm{D}=25$.

\section{Lesion measurement with software}

The retinal lesion was measured and calculated by using AutoCAD software as follows: 1) the image was copied from the fundus camera into the AutoCAD software; 2) a close curve was made on the infection area using the command POLYLINE or PLINE (Figure 1); 3) the area was measured with the command AREA (Figure 2); and 4) the area was shaded with the command HATCH (Figure 3).

\section{Result}

A total of 28 eyes of 28 patients were included in the study, and the characteristics are shown in Table 1. All patients had only one eye infected on examination. 


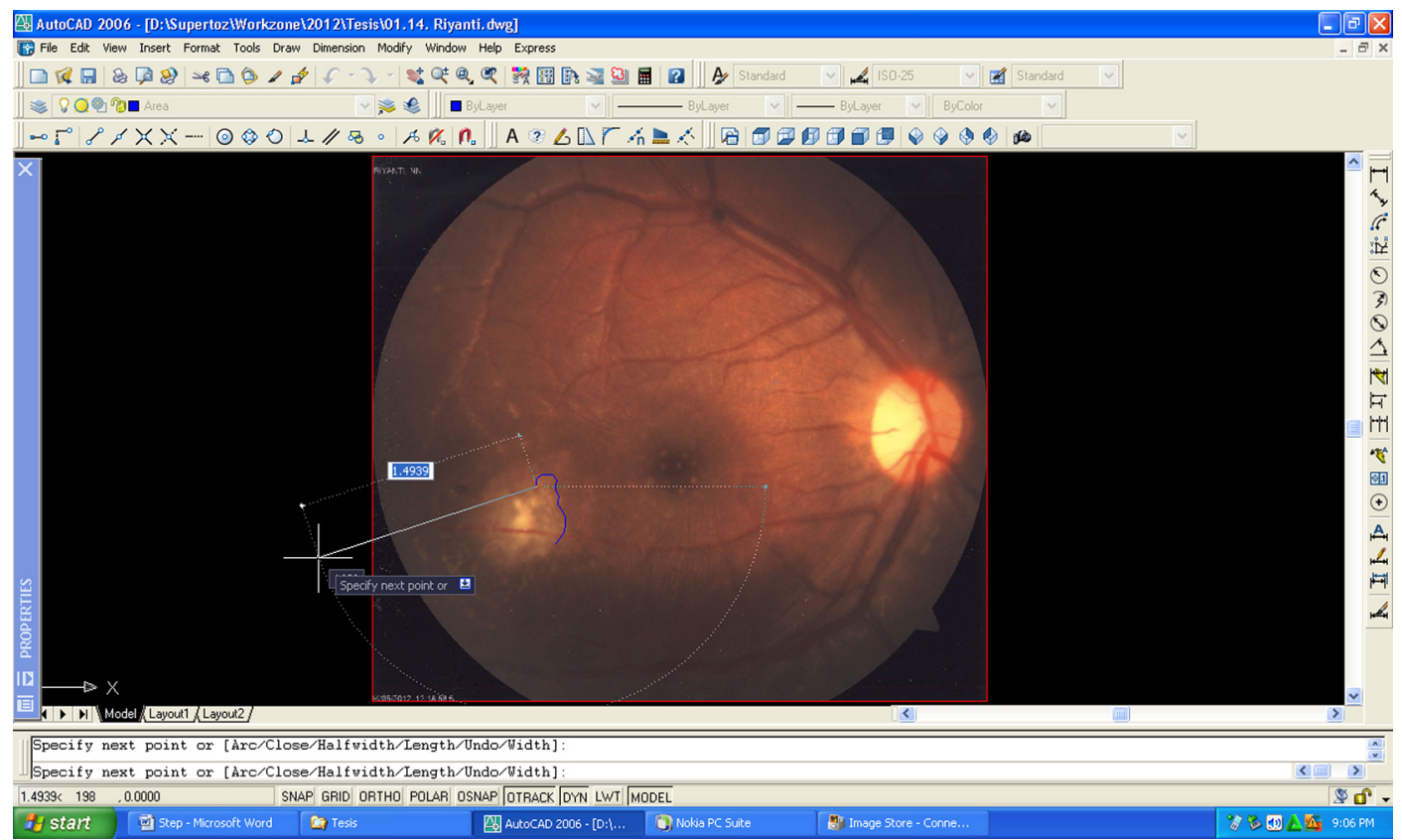

Figure I POLYLINE command step for lesion measurement with AutoCAD software (Autodesk Inc., San Rafael, CA, USA).

Table 1 shows that the mean age of patients in Group II was 32.1 years with a standard deviation of 14.1 , while in Group I it was 27.7 years with a standard deviation of 12.5 . Upon Mann-Whitney analysis with $90 \%$ confidence degree, no significant difference in age between the patients between the groups was observed $(p=0.511)$. The mean lesion size of the two groups is shown in Table 1, and no significant difference in mean lesion size between the two groups was determined $(p=0.531)$.
Comparison of percentage reduction of lesion area between the quadruple-drug therapy group and triple-drug therapy group can be seen in Table 2 .

The data from baseline study to week 3 showed that the quadruple-drug therapy group was $57.5 \%$ with a median of $70.9 \%$ while in the triple-drug therapy group was $52.5 \%$ with a median of $54.0 \%$. The result of statistical test using Mann-Whitney with $90 \%$ degree of confidence showed that there was no significant difference in the percentage of

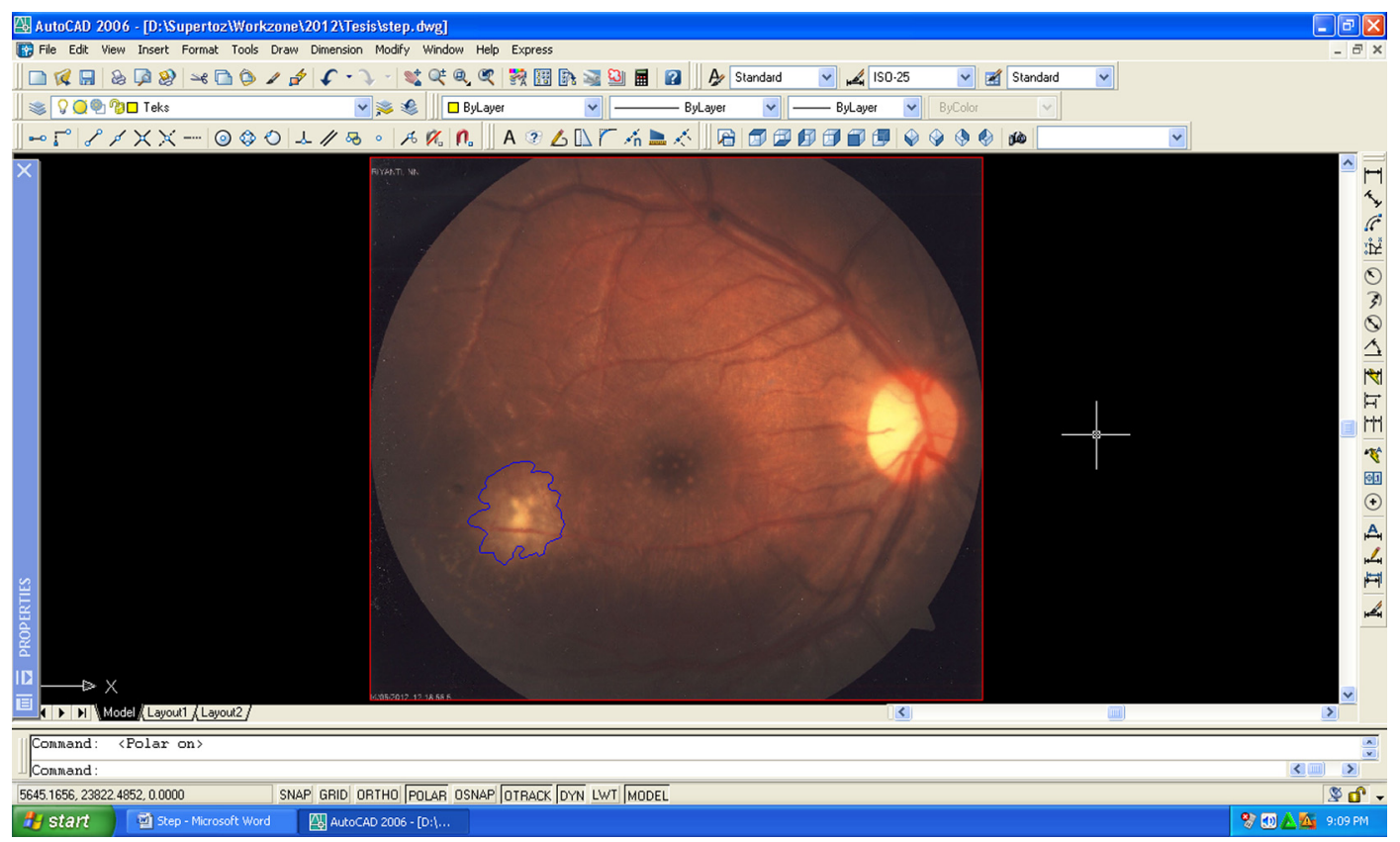

Figure 2 AREA command step for lesion measurement with AutoCAD software (Autodesk Inc., San Rafael, CA, USA). 


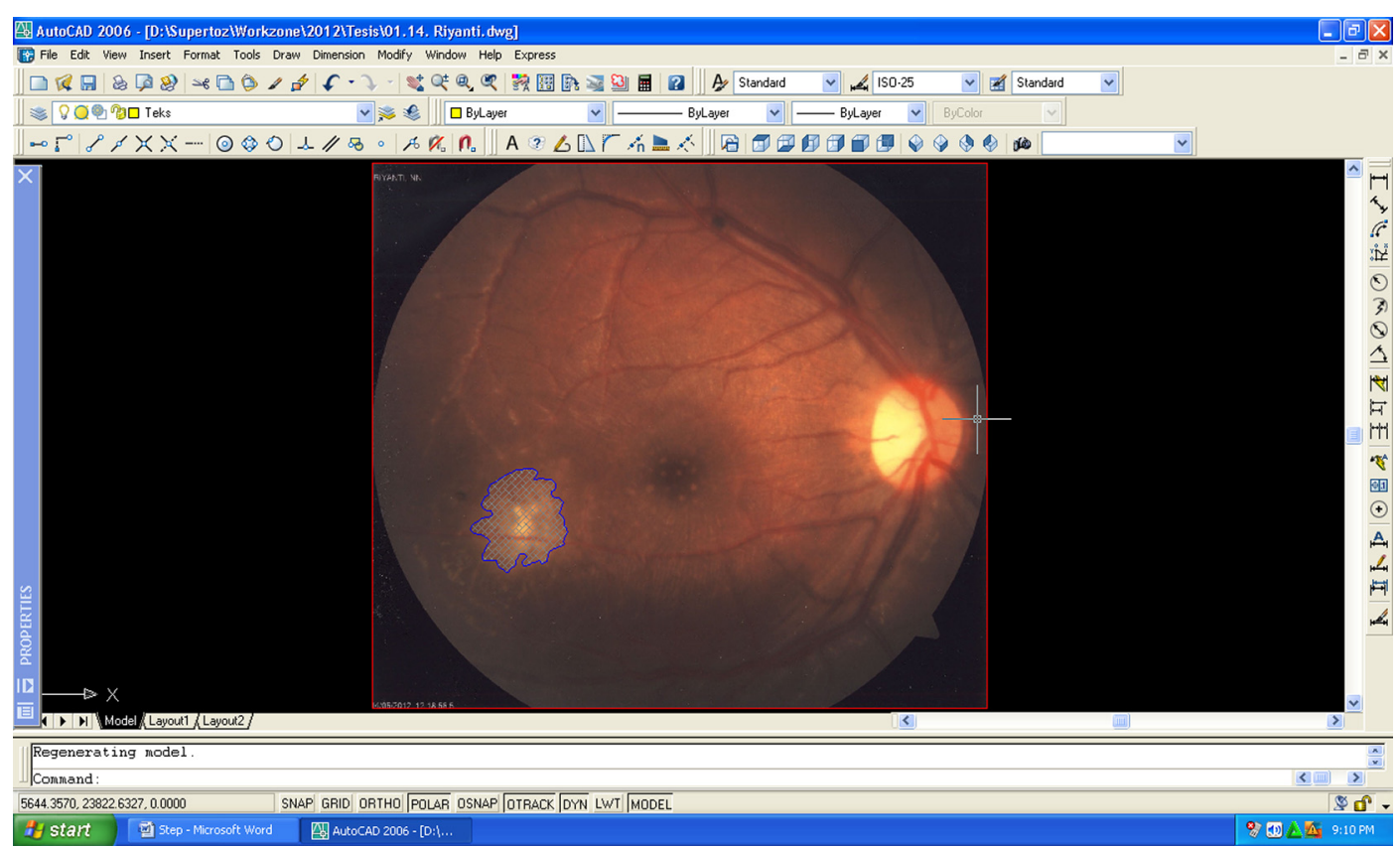

Figure 3 HATCH command step for lesion measurement with AutoCAD software (Autodesk Inc., San Rafael, CA, USA).

reduction of lesion area in both groups with $p$-value $=0.720$. This demonstrates that from the beginning up until the third week of therapy, Group II showed the same effectiveness as Group I in treatment response to toxoplasma chorioretintis. Table 2 shows the mean percentage of the size of the lesion at baseline for the first week up until week 3 in the quadrupledrug therapy group was $71.7 \%$, with median of $87.9 \%$, while in the triple-drug therapy group, the rate was $19.8 \%$ with a median of $23.5 \%$. Based on statistical assessment using Mann-Whitney test with $90 \%$ confidence degree, there was significant difference in the percentage of decrease of lesion area in both groups with $p=0.001$.

\section{Discussion}

The combination of pyrimethamine and sulfadiazine has the strongest and fastest antiparasitic effect, and it is also

Table I Patient characteristics

\begin{tabular}{|c|c|c|c|}
\hline \multirow[t]{2}{*}{ Characteristic } & \multicolumn{2}{|l|}{ Group } & \multirow[t]{2}{*}{$p$-value } \\
\hline & $\begin{array}{l}\text { Quadruple } \\
\text { therapy } \\
(n=14)\end{array}$ & $\begin{array}{l}\text { Triple } \\
\text { therapy } \\
(n=\mid 4)\end{array}$ & \\
\hline Age (years) & & & $* 0.511$ \\
\hline Mean (SD) & $32.1(14.1)$ & $27.7(12.5)$ & \\
\hline Median & 25.5 & 23.5 & \\
\hline Range & $18-58$ & $18-56$ & \\
\hline Gender & & & $* * 0.103$ \\
\hline Male & $12(85.7 \%)$ & 7 (50.0\%) & \\
\hline Female & $2(14.3 \%)$ & 7 (50.0\%) & \\
\hline Mean lesion size $\left(\mathrm{mm}^{2}\right)$ & 0.517 & 0.392 & $* * * 0.531$ \\
\hline
\end{tabular}

Notes: $*\left(Z_{M W}\right)=$ Mann-Whitney test; **Fischer's Exact test; $* * *$ Student's $t$-test. Abbreviation: SD, standard deviation. absorbed rapidly by the body and inhibits the enzyme dihydrofolic acid reductase, which converts dihydrofolic acid to tetrahydrofolic acid which serves to synthesize parasitic DNA. ${ }^{12}$ Conversely, the clindamycin antibiotics have the weakest antiparasitic effect and only work effectively as an antiparasitic when combined with other types of antibiotics such as cotrimoxazole. Oral clindamycin is completely absorbed and reaches the peak level of 2-3 mcg/mL within 1 hour after the initial dose. Its half-life is quite short, around 2.7 hours. A study reported that the sulfa, pyrimethamine, and clindamycin are very effective for the treatment of chorioretinitis, especially for cases with recurrent disease. ${ }^{8}$

From the first admission until the 3rd-week follow-up, there was no significant difference in the lesion size ratio change between the two groups. This is possibly because

Table 2 Comparison of percentage of lesion area reduction in both groups

\begin{tabular}{|c|c|c|c|}
\hline \multirow{2}{*}{$\begin{array}{l}\text { Lesion } \\
\text { reduction (\%) }\end{array}$} & \multicolumn{2}{|l|}{ Group* } & \multirow[t]{2}{*}{$p$-value } \\
\hline & $\begin{array}{l}\text { Quadruple } \\
\text { therapy } \\
(n=14)\end{array}$ & $\begin{array}{l}\text { Triple } \\
\text { therapy } \\
(n=14)\end{array}$ & \\
\hline \multicolumn{3}{|c|}{ Admission - first week } & $Z_{M W}=3.318$ \\
\hline Mean & $71.7 \%$ & $19.8 \%$ & $p=0.001$ \\
\hline Median & $87.9 \%$ & $23.5 \%$ & \\
\hline \multicolumn{3}{|c|}{ Admission - third week } & $Z_{M W}=0.389$ \\
\hline Mean & $57.5 \%$ & $52.5 \%$ & $p=0.720$ \\
\hline Median & $70.9 \%$ & $54.0 \%$ & \\
\hline
\end{tabular}

Notes: $Z_{M W}=$ Mann-Whitney Test; ${ }^{*}$ percentage reduction formula: 100× (initial size - final size)/initial size. 
the pharmacodynamics of both drugs have the maximum of action after one-week. Also, the slow-acting mechanism of drug action will result in a slower reduction in lesions. This especially occurred in Group I. Pyrimethamine works slowly in the blood. The onset of action is achieved on about 2-4 hours with a half-life of 90 hours, while sulfadiazine has a longer half-life of about 10-17 hours. ${ }^{12}$

This study showed no significant difference in the extent of lesions at the time of final control with classic or single cotrimoxazole antibiotic treatment in patients with toxoplasma chorioretinitis. ${ }^{13}$ Other studies showed there was no significant difference in the ratio of the mean lesion at the time of admission and the last control in patients with chorioretinitis treated with two different classes of antitoxoplasma therapy. ${ }^{14}$

In this study, the therapeutic effect of quadruple-drug therapy reached the maximum effect at the time of the first week of follow-up. Therefore, the reduction of the lesion on first week follow-up in this group is higher than the triple-drug-therapy group. Nevertheless, at the final follow-up, there were no significant percentage changes in the lesions in both groups, which confirmed the results of a previous study comparing outcomes between two the different therapies. ${ }^{11}$

A limitation of this study is that there was no complete data about systemic diseases that might accompany the disease under study and that there was no complete serial data on patient's IgG and IgM to correlate the clinical changes with the titer of IgG and IgM. The patient's immunology status is also considered as a confounding factor and is one of the limitations of this study.

\section{Conclusion}

We found that the quadruple-drug therapy has a faster therapeutic effect, thereby providing a reduction in treatment duration where long-term treatment may potentially cause treatment side effects. This rapid reduction of lesions also has the advantage of rapid recovery on visual acuity, resulting in an overall faster recovery process.

\section{Disclosure}

The authors report no conflicts of interest in this work.

\section{References}

1. Balasundaram MB, Andavar R, Palaniswamy M, Venkatapathy N. Outbreak of acquired ocular toxoplasmosis involving 248 patients. Arch Ophthalmol. 2010;128(1):28-32.

2. Butler NJ, Furtado JM, Winthrop KL, Smith JR. Ocular toxoplasmosis II: clinical features, pathology and management. Clin Exp Ophthalmol. 2013;41(1):95-108.

3. Cordeiro CA, Vieira EL, Castro VM, et al. T cell immunoregulation in active ocular toxoplasmosis. Immunol Lett. 2017;184:84-91.

4. Jasper S, Vedula SS, John SS, Horo S, Sepah YJ, Nguyen QD. Corticosteroids as adjuvant therapy for ocular toxoplasmosis. Cochrane Database Syst Rev. 2013(4):CD007417.

5. Helfenstein M, Zweifel S, Barthelmes D, Meier F, Fehr J, Boni C. Ocular toxoplasmosis: therapy-related adverse Drug reactions and their management. Klin Monbl Augenheilkd. 2017;234(4):556-560.

6. Saffra NA, Seidman CJ, Weiss LM. Ocular toxoplasmosis: controversies in primary and secondary prevention. J Neuroinfect Dis. 2013;4: pii:235689.

7. Morhun PJ, Weisz JM, Elias SJ, Holland GN. Recurrent ocular toxoplasmosis in patients treated with systemic corticosteroids. Retina. 1996;16(5):383-387.

8. Holland GN. Ocular toxoplasmosis: a global reassessment. Part II: disease manifestations and management. Am J Ophthalmol. 2004; 137(1):1-17.

9. Souza CE, Nascimento H, Lima A, Muccioli C, Belfort R Jr. Intravitreal injection of sulfamethoxazole and trimethoprim associated with dexamethasone as an alternative therapy for ocular toxoplasmosis Ocul Immunol Inflamm. 2017:1-4.

10. Whitley E, Ball J. Statistics review 4: Sample size calculations. Critical Care. 2002;6(4):335.

11. Soheilian M, Ramezani A, Azimzadeh A, et al. Randomized trial of intravitreal clindamycin and dexamethasone versus pyrimethamine, sulfadiazine, and prednisolone in treatment of ocular toxoplasmosis. Ophthalmology. 2011;118(1):134-141.

12. Kappagoda S, Singh U, Blackburn BG. Antiparasitic therapy. Mayo Clin Proc. 2011;86(6):561-583.

13. Mohammad-Mehdi S, Masoud S, Mohammad-Hossein D, Hassan B, Arash A, Shahin Y. Short-term results of two treatment regimens in ocular toxoplasmosis\&58; trimethoprim/sulfamethoxazole versus pyrimethamine and sulfadiazine. J Ophthalmic Vision Res. 2008;1(1):9-16.

14. Lima GS, Saraiva PG, Saraiva FP. Current therapy of acquired ocular toxoplasmosis: A review. J Ocul Pharmacol Ther. 2015;31(9):511-517.
Clinical Ophthalmology

\section{Publish your work in this journal}

Clinical Ophthalmology is an international, peer-reviewed journal covering all subspecialties within ophthalmology. Key topics include: Optometry; Visual science; Pharmacology and drug therapy in eye diseases; Basic Sciences; Primary and Secondary eye care; Patient Safety and Quality of Care Improvements. This journal is indexed on Submit your manuscript here: http://www.dovepress.com/clinical-ophthalmology-journal

\section{Dovepress}

PubMed Central and CAS, and is the official journal of The Society of Clinical Ophthalmology (SCO). The manuscript management system is completely online and includes a very quick and fair peer-review system, which is all easy to use. Visit http://www.dovepress.com/ testimonials.php to read real quotes from published authors. 